\title{
BRITISH RHEOLOGISTS' CLUB
}

\section{INAUGURAL MEETING}

\begin{abstract}
$\mathrm{A}^{\mathrm{T}}$ $T$ the inaugural meeting of the British Rheologists' Club held at the University of Reading on November 16, a discussion on "Rheology in Industry" was introduced by Mr. J. Pryce Jones. In the unavoidable absence of the president, Prof. G. I. Taylor, the chair was taken by Prof. J. A. Crowther.

Rheology is defined as the 'science of the deformation and flow of matter', and Mr. Pryce Jones stressed the diversity of materials and of the properties of materials which the rheologist has to study. He went on to propose that the Club, or a committee appointed within it, should attempt to make a classification of the essential rheological properties of a number of industrial materials so as to construct a rheological table such as was recently proposed and attempted on a limited scale by Scott Blair (J. Sci. Inst., 17, $169 ; 1940)$. But first it is essential to define the terminology to be used. Such a term as 'thixotropy' is used by different workers in very different senses, and even when the original definition of Freundlich is referred to, definitions of the terms 'sol' and 'gel' are by no means standardized.

Mr. Pryce Jones went on to discuss the property of Spinnbarkeit, and gave some interesting demonstrations of both this and thixotropy, but the main part of his paper was concerned with a description of an extremely ingenious new viscometer especially designed for the study of anomalous liquids. This instrument, shortly to be described in the literature, consists of two Couette units rigidly attached to one another and rotated at the same speed in opposite directions. One of these contains an oil or other true fluid of known viscosity, and in the other is placed the materials to be investigated. The speed at which the couettes rotate can be varied, but if both contain true fluids, the frame connecting the two does not rotate so long as the speed of both is the same. If
\end{abstract}

one of the couettes contains a material the viscosity of which varies with rate of shear, a deflection is observed and can be measured.

Mr. Pryce Jones concluded by discussing the connexion between anomalous viscosity and elastic recoil.

Mr. F. D. Farrow urged the importance of a careful scrutiny of the way in which rheological data are published. Since the methods of analysing such data are still in many cases tentative, it is important that the experimental figures should be given in their original form. The definitions of the term 'sol' and 'gel', 'solid' and 'liquid' were much discussed, Mr. Pryce Jones proposing that any system showing elastic recoil should be classed as a gel, and asking whether anomalous viscosity need be in all cases associated with elastic recoil. Dr. P. Halton and Dr. P. White also spoke on this point, the latter suggesting that, if we regard truly elastic behaviour as analogous to bright sunlight, and truly viscous behaviour to complete darkness, most industrial materials would fall in the twilight zone, and that consequently the distinction between 'sol' and 'gel', though convenient in practice, may be illusory in theory.

Dr. G. W. Scott Blair congratulated Mr. Pryce Jones on his most interesting new viscometer (as did several other speakers) but questioned the advisability of his definition of 'gel', which would include many quite dilute sols such as ammonium oleate (see Hatschek and Jane, Koll. Z., 40, 53 ; 1926).

It was generally agreed that the closer co-operation which the new Club can make possible between rheologists working in different industries will be extremely valuable. That this was appreciated was shown by the fact that the Club already has a membership of sixty-five, and that in spite of the difficulties of the present time, about twenty-five were present at the meeting.

\section{ELECTRICAL DEVELOPMENT IN THAILAND (SIAM)}

\begin{abstract}
A SERIES of useful articles are being published in the Electrician which will prove helpful to electrical manufacturers looking for export markets. In the issue dated November 15, the export market to Thailand (formerly Siam) is discussed.

During the past few years Thailand has developed a sound constructive policy, including the promotion of land, water and air transport and communications. This widespread plan, which as well as including road making, also provides for the improvement of harbour facilities at Bangkok.

Under its scheme of development, the Government spent 370,000 ticals (11 ticals $=£ I$ ) on its wireless broadcasting station during the period April 1, 1938-
\end{abstract}

March 31, 1939 (year of the Buddhist Era 2481), $2 \cdot 2$ million ticals on the Post Office, 4 million ticals on transport and development at the port of Bangkok, and 103,000 ticals on turbines for the Samsen power station. Over a period of four years there has been a steady increase in the demand for electrical goods, apparatus and machinery. This followed naturally from the development of municipal amenities. The figures for 1937-38 show electrical imports of 2,575 thousand kilograms, valued at more than 3 million ticals.

Analysing these figures, the United States led with imports valued at 823,000 ticals; Germany took second place with a value of 553,000 ticals ; from the 